\title{
Epidemias, comércio e emigração Portugal-Brasil na segunda metade do Oitocentos
}

\author{
Epidemics, trade, and Portugal-Brazil emigration \\ in the second half of the nineteenth century
}

\author{
Daniel Estudante Protásio \\ Pós-doutorando, Centro de Estudos Interdisciplinares do século XX/Universidade de Coimbra. \\ daniel.estudante.protasio@gmail.com
}

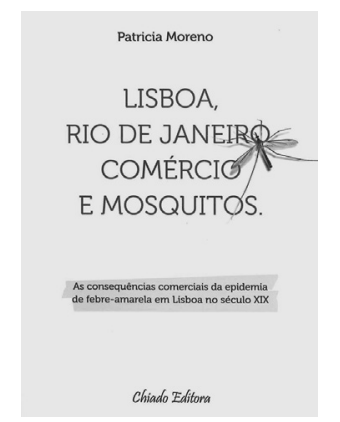

MORENO, Patrícia. Lisboa, Rio de Janeiro, comércio e mosquitos: as consequências comerciais da epidemia de febre-amarela em Lisboa. Lisboa: Chiado. 2013. 214p.
Tum mundo e num início de século como o nosso, em que o 1 ébola, o HIV/Aids e a gripe N1H1 constituem sérias ameaças à segurança e saúde públicas internacionais, nem sempre é fácil entender como num passado relativamente recente outras epidemias podiam interromper os fluxos de circulação de pessoas, bens e serviços entre continentes e nações. Sobretudo para os não iniciados na medicina ou na respetiva história, que não se deleitem com densos estudos técnicos sobre questões epidemiológicas e sanitárias (como é o meu caso), encontrar uma obra como a que aqui me proponho recensar constitui uma verdadeira lufada de ar fresco e um magnífico momento de aprendizagem, sobre áreas e aspetos científicos afins daqueles a que me dedico a estudar nos últimos 20 anos de investigação.

Por outro lado e apesar de uma intensa e frutuosa colaboração e intercâmbio científicos e académicos entre o Brasil e Portugal, no que concerne a historiografia e a história académica dos séculos XIX e XX, nem sempre é fácil encontrar quem consiga transpor, em termos de texto, as naturais barreiras e distâncias entre duas realidades irmãs e similares, mas naturalmente específicas e idiossincráticas, como a portuguesa e brasileira.

Com a presente obra, Patrícia Moreno, investigadora e doutoranda portuguesa em história no Instituto Superior de Ciências do Trabalho e da Empresa, de Lisboa, membro da Sociedade de Geografia de Lisboa e estudiosa dos temas da história da medicina, da emigração e dos descobrimentos portugueses, consegue contribuir com um texto de leitura agradável, informação pertinente e narrativa organizada, sobretudo fruto de uma utilização inteligente de fontes da época e com uma intervenção mínima enquanto narradora dos acontecimentos descritos.

Ora tal não é fácil, num mundo editorial português em que as obras de divulgação científica e histórica abundam e num universo como o da Sociedade de Geografia de Lisboa, 
instituição fundada em 1875 e na qual Patrícia Moreno participa do trabalho de algumas secções e comissões há mais de duas décadas. Pode mesmo afirmar-se que, de uma maneira geral, a profusão de livros publicados em Portugal e a quantidade de comunicações proferidas na dita agremiação lisboeta são de tal magnitude que é difícil encontrar títulos sugestivos e pedagógicos, recreativos e científicos, cativantes e ligeiros na leitura, mas ao mesmo tempo estimulantes de outras pesquisas e que deixem no leitor a sensação de que uma porta intelectual se abriu no cenário dos seus interesses bibliográficos e intelectuais; ou seja, de que saiu enriquecido das horas a que dedicou sua atenção a um trabalho específico. Tal sensação é com frequência mais conotada com outro género de leituras, como a de livros de ficção policial ou de espionagem, de textos de blogues, de revistas, de jornais e newsletters on-line do que obras dedicadas a temáticas históricas. Por contraste, basta folhear as páginas do Boletim da Sociedade de Geografia de Lisboa, que já ultrapassou sua 131ª série (referente a 2013), para encontrar textos sobre temas e títulos históricos, geográficos ou etnográficos escritos em estilo por vezes pesado e de circunstância, nem sempre destinados ao interesse de um público não especializado nem particularmente inclinado a esse tipo de assuntos.

Em termos de estrutura, a obra de Patrícia Moreno divide-se em nove pontos, incluindo introdução, conclusão e bibliografia. De uma forma geral, a autora não abusa das notas infrapaginais, que alcançam o número de 190 em 206 páginas de texto, entre algumas dedicadas a fornecer informações biográficas das figuras de médicos e estadistas referidos, mas sobretudo a consubstanciar as fontes e bibliografia a que recorreu.

Na contracapa do livro, são deixadas as seguintes palavras e interrogações: "Como e quando chegou a febre amarela a Lisboa vinda do Brasil? E quais foram as medidas adotadas pelas autoridades portuguesas? A essas questões procurará esse livro lançar pistas e oferecer algumas respostas". Essa é a mensagem essencial do primeiro ponto do livro, que se intitula "A razão deste livro, perguntas e dúvidas" e começa com uma citação de Rui Barbosa, proferida numa conferência de maio de 1917: "O mundo vê no Brasil um país de febre amarela. O Governo brasileiro o confessa. A medicina brasileira não o pode negar" (p.11). Numa outra citação, na mesma página, Barbosa informa-nos que em 1857-1858, 1860, 1864 e 1869 tal doença chega do Brasil a Portugal. Mas esse não será o âmbito cronológico da obra, mais alargado.

Num segundo ponto ou capítulo do livro, intitulado "Resenha histórica da febre amarela", Patrícia Moreno resume, em cerca de uma dúzia de páginas, o que a literatura seiscentista e setecentista afirmava sobre a epidemia; suas principais características e alterações fisiológicas no indivíduo acometido dessa patologia; e a abrangência geográfica da mesma, num triângulo atlântico Américas-África-Europa. A autora recorre a tratados médicos, mas também a breves referências em literatura popular do século XIX, como Alexandre Dumas e Júlio Verne, e menciona terríveis momentos de dizimação coletiva, como aquando da invasão francesa da ilha de São Domingo (atuais Haiti e República Dominicana) em 1801, de Barcelona em 1821 e do surto do vale do Mississípi em 1878, tendo morrido, nestes dois últimos casos, cerca de vinte mil catalães e outros tantos norte-americanos (p.17, 20). Introduz a questão do debate médico sobre a forma de combater essa praga e como ela se propaga, matérias que dividirão opiniões científicas e a opinião pública mundiais durante várias décadas do século XIX.

Subitamente, num terceiro capítulo, "Portugal e o Brasil ou o Brasil e Portugal", a autora aligeira o tom, alarga o âmbito do seu estudo, não agora meramente geográfico, cronológico, 
estatístico e médico, mas contextualiza a situação geral portuguesa e brasileira, de forma rigorosa, mas necessariamente breve, de modo a impedir que o leitor se perca em demasiados pormenores e perca literalmente o fio à meada, esquecendo o propósito primeiro desse trabalho - a febre amarela e seu impacto sanitário, comercial e político nos dois países. Vai, assim, elencando as várias formas de relações luso-brasileiras - familiares/dinásticas, comerciais, sociais - e os diferentes métodos de contacto transnacional: o transporte marítimo de emigrantes portugueses em busca de trabalho, legal e ilegalmente; as políticas lisboetas para travar tal fluxo demográfico, bem como o surgimento da figura do "brasileiro" em Portugal, na sociedade e na literatura portuguesas. Está então dado o mote para uma apaixonante reflexão sobre questões de história das mentalidades, social e política: as condições insalubres nos "cortiços" brasileiros aos quais chegavam os emigrantes portugueses, mas também nos bairros pobres de Lisboa e Porto, onde a febre amarela se propagará; o constante ambiente de guerra civil e de revolução em Portugal até à Regeneração de 1851 e a dificuldade que diferentes governos sentiram para inverter uma política de emigração maciça, devido à pobreza, desemprego e analfabetismo que grassavam deste lado do Atlântico. A intervenção de figuras gradas da política e das letras portuguesas como Alexandre Herculano e Ramalho Ortigão, o conde de Tomar (Costa Cabral), Fontes Pereira de Melo e José Luciano de Castro, tentando alertar a opinião pública e legislar para que a falta de condições de salubridade e de habitação não servissem de rastilho à propagação da febre amarela, como ainda sucedeu no Rio de Janeiro, de forma intervalada, nas décadas de 1870 a 1890. Em Lisboa, a Sociedade de Geografia, cujos estatutos foram reformados em 1895, contou imediatamente com uma Comissão de Emigração, tal a preponderância política, económica e social da saída de emigrantes e consequente perda de força de trabalho e destruição do tecido social nacional.

Nos pontos - ou capítulos, como lhes poderíamos chamar - 4 e 5 , o primeiro com cerca de trinta páginas e o segundo com cerca de quarenta, a autora congrega o essencial da sua análise, dedicada primeiro ao "Rio de Janeiro e a epidemia de 1850" e depois a "Lisboa e a febre amarela - a terrível década de 1850". Com inteligente e rigoroso recurso a fontes de ambas as nacionalidades, Patrícia Moreno estuda os casos brasileiro e português socorrendo-se de pontos de vista contemporâneos e divergentes, alguns cientificamente fundamentados, outros meramente propagandísticos e eleitoralistas. Em causa estava perceber a verdadeira origem do surgimento e transmissão da doença e quais as formas corretas de a tratar e prevenir. Numa época em que o comércio luso-brasileiro e as remessas financeiras de emigrantes portugueses bem-sucedidos no Brasil pesavam fortemente na balança comercial de Portugal, o vetor de transmissão da doença, o mosquito, estava fora da equação. O mosquito, ou pernilongo, que faz parte do título desse livro e cuja imagem figura na respetiva capa, não era ainda entendido como elemento preponderante e transmissor da patologia. As autoridades portuguesas e brasileiras insistiram, durante décadas, em políticas de quarentena (à imagem, aliás, das demais nações) e na criação e manutenção do lazareto de Porto Brandão, na margem sul do Tejo, defronte de Lisboa e no lazareto da ilha do Bom Jesus dos Frades, no Rio. Os higienistas, reunidos pela primeira vez em congresso internacional em 1852, dividiam-se entre os que defendiam a existência de contágio e a necessidade de isolamento dos doentes e de quem viajava em navios onde grassava a doença (os contagionistas) e os que defendiam in stricto 
sensu que "A higiene e a desinfestação são as únicas armas de que dispõem os médicos" (p.80), sendo necessário combater a infeção onde ela ocorria (os infeccionistas).

Em Portugal, foi apurado que morreram quase seis mil pessoas durante as epidemias de 1856-1858, o que constituiu um número dramático de vítimas. Duas das mais célebres vítimas mortais foram o cardeal patriarca de Lisboa e o renomado médico e membro da Academia das Ciências de Lisboa António da Fonseca Benevides. O casal régio, dom Pedro V e dona Estefânia, interviriam corajosamente no socorro e apoio moral aos doentes, mas ambos morreriam muito novos de outras doenças frequentes na época, respetivamente febre tifoide e difteria. "Lisboa, cidade insalubre" era uma das imagens transmitidas durante décadas, fosse pelo académico Oliveira Pimentel, pelo afamado Eça de Queiroz ou pela polémica princesa Ratazzi, com o primeiro a afirmar, em 1857, as seguintes palavras arrepiantes: "O estado das praias lodosas em frente da cidade [de Lisboa] é o mais deplorável que se pode imaginar; e, se as comparássemos com o delta do Ganges, onde se gera o cólera-morbo, não ficaríamos longe da verdade" (p.126). O congresso sanitário reunido sob os auspícios régios naquele ano, na Academia das Ciências, pouco ou nada conseguiu resolver e não só "Os lisboetas fogem da epidemia" como "Lisboa sofria e morria!", como sugerem dois subtítulos utilizados pela autora neste seu quinto capítulo (p.127, 130). Chegando-se à conclusão de que a doença não era "nativa" de Portugal, embora prosperasse com as condições de insalubridade e no tempo quente (e que, portanto, provinha por via marítima, sobretudo do Brasil), persistiram as políticas de quarentena e de utilização do lazareto.

É a esses dois temas - quarentena e lazareto - que Patrícia Moreno vai dedicar o sexto ponto ou capítulo do seu livro, o último com uma extensão considerável na obra agora em análise. Enquanto de França não surgiram as notícias das descobertas de Pasteur e do Brasil os resultados práticos da obra salvífica de Oswaldo Cruz, esta já no início do século XX, Portugal teve de recorrer aos anacrónicos mecanismos de contenção de uma doença que nunca mais se tornou tão devastadora como em 1856-1858, mas cuja ameaça constante, durante décadas, foi alvo da chacota, da incompreensão e da raiva de parlamentares, de jornalistas e de viajantes que, em face do número reduzido de mortes devidas à epidemia, se revoltavam quanto à preponderância de medidas sanitárias ditas "incivilizadas". Numa segunda metade do século XIX, sobretudo marcada pelo ritmo cada vez mais frenético da circulação livre de pessoas, ideias e mercadorias, em nível europeu e mundial, as restrições de entrada no porto de Lisboa eram incompreensíveis para comerciantes e para os setores da sociedade, da política e da economia mais interessados em que Portugal prosperasse pela via da circulação comercial do que em escutar as posições cautelosas de médicos e de académicos que defendiam a necessidade da quarentena de pessoas e bens e sua permanência no lazareto na margem sul do Tejo. Medidas públicas de aprofundamento do saber técnico sobre a demografia, como o primeiro recenseamento geral da população em 1864, a utilização internacional do telégrafo elétrico e a aprovação de um regulamento geral de sanidade marítima em Portugal, já influenciada pelas ideias de Pasteur, terão contribuído para manter baixos os números de mortalidade epidémica, mas tal não impediu que, por exemplo, ocorresse uma "gravíssima epidemia de peste na cidade do Porto em 1897 que tinha demonstrado que os regulamentos sanitários observados desde há várias décadas não protegiam totalmente as populações" (p.157-158). Ora o que em hoje em dia é um lugar-comum, que o isolamento dos potenciais doentes e 
das pessoas afetadas por doenças não evita totalmente sua proliferação sem que a causa e os fatores de desenvolvimento e de propagação da mesma sejam conhecidos e anulados na sua ação nefasta, não era consensual nessa época - longe disso. Tal como no início da introdução da inoculação vacínica em Portugal, nos anos de 1800 e 1810, pela Academia das Ciências, aquela medida experimental fora motivo de polémica e de espanto por parte da maioria da população e das elites, quase cem anos depois a sobrevivência da quarentena e do lazareto eram também altamente contestados e incompreendidos, porque "residualmente" - se assim se poderá dizer - os casos de febre amarela e de outras epidemias, por vezes muito mais mortíferas, continuavam a manter-se: seria um caso de "matar o mensageiro", até certo ponto; nesse caso, os médicos favoráveis a tais medidas e os decisores políticos sobre saúde pública em Portugal.

Patrícia Moreno contextualiza e problematiza esses dois temas, o da quarentena de passageiros em navios e o das condições - também elas insalubres! - do lazareto de Lisboa, que o governo tratou de estudar no sentido de melhorar. Os conhecidos escritores humorísticos e satíricos portugueses, Eça de Queiroz e Ramalho Ortigão, referiram-se ao lazareto, e o imperador dom Pedro II, na sua visita de 1871, fez questão de demonstrar o caráter privado da sua viagem sujeitando-se, como os demais, às condições de isolamento no lazareto. Mas para além dos incómodos dessas e de outras figuras ilustres, como a de Sarah Bernhardt, que infelizmente a autora não nos explica como contornou - se o conseguiu - a proibição de pisar Lisboa sem passar pelo lazareto (p.171-72), a questão era também de natureza comercial: os produtos que não pudessem passar pelo porto de Lisboa ou por qualquer outro porto português que estivesse vigiado pelas autoridades sanitárias eram desviados para as Canárias, para o Mediterrâneo ou para qualquer porto onde a política pública de saúde não fosse tão apertada. Refere especificamente o caso da barca Imogene, que em 1879 é caricaturado pela imprensa política e humorística nacional e no qual o diagnóstico do distinto médico Sousa Martins é colocado em causa, vendo-se o mesmo obrigado a escrever um livro - cujo título a autora não cita - para defender sua reputação e sua honra como médico (p.180 e s.). Apenas com a abertura do posto marítimo de desinfeção de Lisboa, a 1 de janeiro de 1906, já iniciado o século XX, a velocidade de entrada de passageiros e de mercadorias no porto lisboeta atinge o ritmo e a desburocratização que os tempos exigiam. A imprensa julga, naturalmente, com bons olhos tal inovação, mas aparentemente esquece-se de que ela não poderia existir se a ciência não tivesse já conhecido e debelado, no Brasil, as causas da mortandade que a febre amarela provocara durante décadas.

É nos dois últimos pontos ou capítulos, o sétimo e o oitavo, do livro que Patrícia Moreno explica-nos o que verdadeiramente mudou e obstou a que a febre amarela deixasse de matar aos milhares em Portugal. Se o médico português Ricardo Jorge escrevia que em 1860-1880 "só 20 navios entrados na barra de Lisboa foram considerados infeccionados" e se se sabe que isso ocorreu em apenas outros quatro até 1900 (p.192), não parecem restar dúvidas de que "O Brasil liberta-se... e Portugal respira": isto é, só com a ação de Oswaldo Cruz (18721917), médico brasileiro, foi possível "estancar a mortandade devida à febre amarela no Rio de Janeiro" (p.195-196). A luta contra o mosquito, entre 1903 e 1909, permite senão erradicar, pelo menos diminuir drasticamente a incidência da doença em Portugal e no Brasil: "Não é a cura, mas sim a profilaxia da propagação da doença que irá trazer a glória a este médico 
brasileiro" (p.203). E nas conclusões, Patrícia Moreno deixa-nos duas afirmações, talvez um pouco longas para serem transcritas na íntegra, mas que são decisivas para compreender o essencial da mensagem transmitida: "As autoridades sanitárias e o governo de Portugal souberam resistir às incursões de febre amarela e de cólera-morbo. Souberam também resistir a todos aqueles que propuseram, na maioria dos casos com intuitos meramente comerciais e de lucro fácil, um aligeiramento ou mesmo a eliminação da legislação rigorosa em vigor". E termina seu texto relembrando como "página quase esquecida da nossa história recente" a temática abordada: a do "perigo da importação" de febre amarela e as medidas adotadas pelas autoridades políticas e sanitárias portuguesas, com consequências danosas no desenvolvimento das relações comerciais entre Portugal e Brasil" (p.205-206). É este seu papel, assumido, como autora: fornecer as pistas, as fontes e os factos para que consensualmente se possa chegar a tais conclusões, deixando ao leitor a liberdade de concordar ou não com tais assunções, que são apenas afirmadas no final do livro.

O nono e último ponto ou capítulo é o da bibliografia, talvez o mais frágil de todos. Poderia ser mais rigorosamente dividido em fontes, bibliografia e webgrafia. A "Bibliografia: Séculos XVII a XIX" poderia ser designada por fontes e a referente aos séculos XX e XXI, essa sim, listada como bibliografia, excetuando a que diz respeito às décadas de 1900 a 1920 ou 1930, dado que são de 1926 e 1938 dois títulos de Ricardo Jorge que podem ser considerados fontes. Também as caixas dos arquivos citados do Ministério português dos Negócios Estrangeiros e do Arquivo Nacional da Torre do Tombo deveriam ser mencionadas e as páginas de internet conter as datas de consulta. Mas essas são questões secundárias, mais do foro editorial do que autoral. Faria ainda falta um índice remissivo, pelo menos onomástico, para mais fácil localização de figuras referidas da medicina, literatura, política e jornalismo portugueses e brasileiros em duzentas páginas de uma obra que se lê com grande facilidade e proveito. Numa segunda edição, Patrícia Moreno poderá eventualmente acrescentar alguma bibliografia especializada brasileira, como artigos da revista História, Ciências, Saúde - Manguinhos a propósito de temáticas similares, consultáveis, também eles on-line, se eventuais acrescentos e aprofundamentos o justificarem, naturalmente. 